\title{
OPEN Free radical degradation in aqueous solution by blowing hydrogen and carbon dioxide nanobubbles
}

\author{
Toyohisa Fujita ${ }^{1 凶}$, Hiromi Kurokawa ${ }^{2}$, Zhenyao $\mathrm{Han}^{1}$, Yali Zhou' ${ }^{1}$, Hirofumi Matsui², \\ Josiane Ponou ${ }^{3}$, Gjergj Dodbiba ${ }^{3}$, Chunlin $\mathrm{He}^{1}$ \& Yuezou Wei ${ }^{1 凶}$
}

The main findings are the hydroxyl radical scavenging and the superoxide anion diminishing by mixing the carbon dioxide $\left(\mathrm{CO}_{2}\right)$ nanobubbles after hydrogen nanobubble blowing in water and alcohol aqueous solution. The nanobubbles produce the hydroxyl radical by ultrasonic waves, changing the $\mathrm{pH}$ and catalyst and so on, while the nanobubble is very reactive to scavenge free radicals. In this research especially hydrogen ( $4 \% \mathrm{H}_{2}$ in argon) and $\mathrm{CO}_{2}$ nanobubbles have been blown into hydrogen peroxide $\left(\mathrm{H}_{2} \mathrm{O}_{2}\right)$ added pure water, ethanol, and ethylene glycol aqueous solution through a porous ceramic sparger from the gas cylinder. The aqueous solutions with $\mathrm{H}_{2} \mathrm{O}_{2}$ are irradiated by ultraviolet (UV) light and the produced hydroxyl radical amount is measured with spin trapping reagent and electron spin resonance (ESR). The $\mathrm{CO}_{2}$ nanobubble blowing extremely has reduced the hydroxyl radical in water, ethanol, and ethylene glycol aqueous solution. On the other hand, when $\mathrm{H}_{2}$ nanobubbles are brown after $\mathrm{CO}_{2}$ nanobubble blowing, the hydroxyl radical amount has increased. For the disinfection test, the increase of hydroxyl radicals is useful to reduce the bacteria by the observation in the agar medium. Next, when the superoxide anion solution is mixed with nanobubble containing water, ethanol, and ethylene glycol aqueous solution, $\mathrm{H}_{2}$ nanobubble has reduced the superoxide anion slightly. The water containing both $\mathrm{CO}_{2}$ and $\mathrm{H}_{2}$ nanobubble reduces the superoxide anion. The less than $20 \%$ ethanol and the $30 \%$ ethylene glycol aqueous solution containing $\mathrm{CO}_{2}$ nanobubbles generated after $\mathrm{H}_{2}$ nanobubble blowing can diminish the superoxide anion much more. While the $\mathrm{H}_{2}$ nanobubble blowing after $\mathrm{CO}_{2}$ nanobubble blowing scavenges the superoxide anion slightly. The experimental results have been considered using a chemical reaction formula.

Reactive oxygen species are hydroxyl radical $(\cdot \mathrm{OH})$, superoxide anion $\left(\cdot \mathrm{O}_{2}^{-}\right)$, hydrogen peroxide $\left(\mathrm{H}_{2} \mathrm{O}_{2}\right)$, single oxygen $\left({ }^{1} \mathrm{O}_{2}\right)$, and ozone $\left(\mathrm{O}_{3}\right)$, while hydroxyl radical $(\cdot \mathrm{OH})$ and superoxide anion $\left(\cdot \mathrm{O}_{2}^{-}\right)$are free radical. This report is not the free radical production by nanobubble but describes the free radical degradation in aqueous solution by adding nanobubbles. Various kinds of materials have been reported to scavenge free radicals in medical and pharmacy fields in the paper such as FREE RADICAL RESEARCH and so on. However, there are a few reports for free radical degradation by adding and mixing nanobubbles, while, there are several reports for the detection and production of free radicals by nanobubbles. The aim of this research is how to reduce or increase the existing free radical by nanobubble, therefore, in the beginning, the reports of free radical production conditions by nanobubble are investigated. Takahashi et al. reported that the hydroxyl radical generation with ESR measurement using 5,5-dimethyl-1-pyrroline $\mathrm{N}$-oxide (DMPO) as a spin-trapping reagent has been observed after collapsing of high concentration air microbubbles in water produced by a pump through a gas-dissolution tank and a microbubble-generating nozzle ${ }^{1}$. Next, his group reported that the $\cdot \mathrm{OH}$ producing in both cases of air (oxygen microbubbles and nitrogen microbubbles) in the acidic condition at $\mathrm{pH} 2$ and $3^{2}$ and the generation of hydroxyl radicals from the collapse of oxygen or air microbubbles was markedly enhanced by the existence of copper ion catalyst by the copper wire under $\mathrm{pH} 2.2$ acidic $\mathrm{HCl}$ solution ${ }^{3}$. Also, the microbubbles on ozonized water indicated the presence of hydroxyl radical by the collapse of microbubble ${ }^{4}$. Recent papers are referred the above papers ${ }^{5}$ and the oxygen nanobubble stability was confirmed to be $\mathrm{pH}$-dependent and the collapsed oxygen nanobubble generate the free radical that induced the photodegradation of oxytetracycline $e^{6}$. When the absolute value of zeta potential of nanobubble is low, there is a possibility to collapse of nanobubble by Brownian motion and produce the free radical and also the existence of catalysts enhance the radical generation. Ozone

${ }^{1}$ College of Resources, Environment and Materials, Guangxi University, Nanning 530004, China. ${ }^{2}$ Faculty of Medicine, The University of Tsukuba, Tsukuba 305-8575, Japan. ${ }^{3}$ Graduate School of Engineering, The University of Tokyo, Tokyo 113-8656, Japan. ${ }^{凶}$ email: fujitatoyohisa@gxu.edu.cn; yzwei@gxu.edu.cn 
addition can produce the hydroxyl radical. On the other hand, the free radical could not generate by the selfcollapse of air micro-nano bubbles in pure water produced by fiber membrane filter, and the hydroxyl radical peak was observed with weak supersonic wave ${ }^{7}$. The radical production by ultrasonic wave irradiation becomes more important to produce the radicals, especially hydroxyl radicals in water by comparing no irradiation and irradiation ${ }^{8}$ and the ultrasonic waves collapse the nanobubble (hydrogen) and increase the temperature of water?. Therefore, the pure water and alcohol mixed water that does not change the $\mathrm{pH}$ and not irradiated an ultrasonic wave is utilized in this report. As the application of produced radicals, there are reports for environmental cleaning related to wastewater treatment ${ }^{10-13}$ and the medical application by reducing oxygen molecules in a chaotic manner within the tumour ${ }^{14}$. In this paper, the bacteria reduction is also examined when the hydroxyl radical enhances in the aqueous solution.

On the other hand, the nanobubble effects to degrade the existing free radicals have been investigated for recent 10 years. In 2010 the nano-bubble hydrogen-dissolved water, which was prepared using a microporousfilter hydrogen-jetting device, scavenged reactive oxygen species (ROS) indispensable to slightly exist as a signal for tumor cell growth ${ }^{15}$. In 2014 the same group reported that Oxygen nanobubble improved blood oxygenation, however, microbubbles also cause tissue damage as well as free radical production and that oxygen itself can be toxic $^{16}$. In 2015 the hydrogen nanobubbles produced by gas-liquid two-phase flow swivel apparatus and the antioxidant activity of nano-bubble hydrogen dissolved water were investigated by the DMPO-spin trap ESR in the $\mathrm{H}_{2} \mathrm{O}_{2}-\mathrm{UVB}$ irradiation system or 2,2'-bipyridyl method. The hydrogen nanobubbles could reduce the hydroxyl radical concentration ${ }^{17}$. It has been reported in 2018 that the hydrogen nanobubble water can effectively remove cytotoxic reactive oxygen species (ROS) such as $\cdot \mathrm{OH}, \mathrm{ClO}-$, $\mathrm{ONOO}-$, and $\cdot \mathrm{O}_{2}{ }^{-}$both in vivo and in vitro ${ }^{18}$. Cancer cell growth was inhibited in the hydrogen nanobubble-containing medium compared to the non-containing medium (in vitro) ${ }^{19}$. They have reported mainly the scavenging of ROS by using hydrogen nanobubbles.

In this experiment, the degradation of free radicals for hydroxyl radical and superoxide anion have been compared with single nanobubbles $\left(\mathrm{H}_{2}+\mathrm{Ar}, \mathrm{CO}_{2}, \mathrm{~N}_{2}, \mathrm{O}_{2}\right)$ and mixture nanobubbles $\left(\mathrm{H}_{2}+\mathrm{Ar}\right.$ and $\left.\mathrm{CO}_{2}\right)$ in water and alcohol aqueous solution. The hydroxyl radical in free radical included aqueous solution (pure water, ethanol, and ethylene glycol) is prepared by $\mathrm{H}_{2} \mathrm{O}_{2}$ addition followed by blowing various nanobubble into the liquid, and the hydroxyl radical scavenging is investigated for single nanobubbles and mixture nanobubbles. The superoxide anion in free radical-induced aqueous solution is prepared by a hypoxanthine (HX) and xanthine oxidase (XO) system and mixed with nanobubble included aqueous solution. The superoxide anion scavenging is examined using the single nanobubbles and mixture nanobubbles. The free radical concentration is measured with ESR by using G-CYPMPO as a spin trapping reagent. The degradation of free radicals is effective for healthy beverage and the increase of hydroxyl radical eliminates the bacteria concentration.

\section{Results}

Produced nanobubbles size in aqueous solution. The mean diameter of produced nanobubble in various aqueous solutions are listed in Table 1. The mean diameter of $\mathrm{H}_{2}\left(4 \%\right.$ in $\mathrm{Ar}$ ), $\mathrm{CO}_{2}, \mathrm{O}_{2}$, and $\mathrm{N}_{2}$ nanobubble in water is between 100 and $200 \mathrm{~nm}$. The mean diameter of $\mathrm{H}_{2}(4 \%$ in $\mathrm{Ar}$ ) in ethanol aqueous solution is between 150 and $250 \mathrm{~nm}$, while in the ethylene glycol aqueous solution the nanobubble diameter becomes larger between 500 and $1000 \mathrm{~nm}$. The mean diameter of $\mathrm{CO}_{2}$ nanobubble in ethanol solution is between 250 and $300 \mathrm{~nm}$ and in the ethylene glycol aqueous solution the nanobubble diameter becomes larger between 400 and $1000 \mathrm{~nm}$ similar to $\mathrm{H}_{2}$ ( $4 \%$ in Ar) nanobubble in ethylene glycol. The mean diameter of nanobubble by both blowing $\mathrm{H}_{2}(4 \%$ in Ar) gas and next $\mathrm{CO}_{2}$ gas in ethanol aqueous solution is about $200 \mathrm{~nm}$, however, the mean diameter of nanobubble by $\mathrm{CO}_{2}$ gas and next $\mathrm{H}_{2}$ (4\% in Ar) gas becomes larger between 200 and $500 \mathrm{~nm} . \mathrm{H}_{2}$ (4\% in $\mathrm{Ar}$ ) nanobubble size in water is gradually increased and stable about $400 \mathrm{~nm}$ after 10 days and exists more than 100 days. While the $\mathrm{CO}_{2}$ nanobubble is gradually increased and disappeared after several days. In Table 1 the solubility of the gas in water is also listed ${ }^{20}$. The $\mathrm{CO}_{2}$ gas solubility is one order larger comparing other gas like $\mathrm{H}_{2}, \mathrm{Ar}, \mathrm{O}_{2}$, and $\mathrm{N}_{2}$.

ESR measurement of free radicals mixed with nanobubble aqueous solution. The ESR spin adducts of sc-5-(5,5-dimethyl-2-oxo-1,3,2-dioxapho-sphinan-2-yl)-5 methyl-1-pyrroline $\mathrm{N}$-oxide (G-CYPMPO) for hydrogen peroxide aqueous solution $(0.1 \mathrm{wt} \%)$ under $10 \mathrm{~s}$ UV-illumination (A) and hypoxanthine/xanthine oxidase (HX/XO) system (B) is shown in Fig. 1. Eight peaks are appeared by CYPMPO, however, the peak positions of two kinds of radicals in the magnetic field are different. In the following figures of this paper, the heights in the assigned number of eight peaks are compared instead of wave patterns of two radicals (A) and (B).

Free radical degradation in water. Degradation of hydroxyl radical with ultraviolet in water blown different kinds of nanobubbles $\mathrm{N}_{2}, \mathrm{O}_{2}, \mathrm{H}_{2}$ (4\% in $\mathrm{Ar}$ ), and $\mathrm{CO}_{2}$ are measured by ESR and shown in Fig. 2. For all peaks of hydroxyl radical in water, only $\mathrm{CO}_{2}$ nanobubble has decreased compared with the control water and the water containing other nanobubbles. Also, the 4 th peak of the water containing $\mathrm{H}_{2}$ ( $4 \%$ in $\mathrm{Ar}$ ) nanobubble has decreased. Therefore, the water containing $\mathrm{CO}_{2}$ nanobubble is used for the hydroxyl radical degradation experiment in other aqueous solutions. On the other hand, the degradation by nanobubble combination of $\mathrm{CO}_{2}$ after $\mathrm{H}_{2}$ (4\% in $\mathrm{Ar}$ ) nanobubble in water and combination of $\mathrm{H}_{2}\left(4 \%\right.$ in $\mathrm{Ar}$ ) after $\mathrm{CO}_{2}$ nanobubble in water show the similar to the degradation by $\mathrm{CO}_{2}$ bubbling. Degradation of superoxide anion radical in the water containing different kinds of nanobubbles $\mathrm{N}_{2}, \mathrm{O}_{2}, \mathrm{H}_{2}$ (4\% in $\mathrm{Ar}$ ), and $\mathrm{CO}_{2}$ are measured by ESR and shown in Fig. 3. The peaks of water blown $\mathrm{H}_{2}$ (4\% in $\mathrm{Ar}$ ) nanobubble shows larger degradation peaks comparing with the control water. Therefore, the water bubbled $\mathrm{H}_{2}$ (4\% in $\mathrm{Ar}$ ) nanobubble is used for the superoxide anion radical degradation in the following experiment. Both degradation by nanobubble combination of $\mathrm{CO}_{2}$ after $\mathrm{H}_{2}(4 \%$ in $\mathrm{Ar}$ ) nanobubble and combination of $\mathrm{H}_{2}$ (4\% in $\mathrm{Ar}$ ) after $\mathrm{CO}_{2}$ nanobubble show a little bit larger degradation of $\mathrm{H}_{2}$ (4\% in $\mathrm{Ar}$ ). 


\begin{tabular}{|c|c|c|}
\hline & Mean diameter, nm & Solubility vol $/ \mathrm{cm}^{3}$ at $1 \mathrm{~atm}$ and $20^{\circ} \mathrm{C}^{20}$ \\
\hline $\mathrm{H}_{2}(4 \%$ in $\mathrm{Ar}$ ) gas into water & 130 & $\mathrm{H}_{2} 0.018, \mathrm{Ar} 0.035$ \\
\hline $\mathrm{H}_{2}(4 \%$ in $\mathrm{Ar}$ ) gas into $10 \%$ ethanol and $90 \%$ water & 230 & \\
\hline $\mathrm{H}_{2}(4 \%$ in $\mathrm{Ar}$ ) gas into $20 \%$ ethanol and $80 \%$ water & 180 & \\
\hline $\mathrm{H}_{2}(4 \%$ in $\mathrm{Ar}$ ) gas into $50 \%$ ethanol and $50 \%$ water & 150 & \\
\hline $\mathrm{H}_{2}$ (4\% in $\mathrm{Ar}$ ) gas into $30 \%$ ethene glycol and $70 \%$ water & 570 & \\
\hline $\mathrm{H}_{2}$ (4\% in $\mathrm{Ar}$ ) gas into $50 \%$ ethene glycol and $50 \%$ water & 820 & \\
\hline $\mathrm{H}_{2}\left(4 \%\right.$ in $\mathrm{Ar}$ ) gas and next $\mathrm{CO}_{2}$ gas into water & 140 & \\
\hline $\mathrm{H}_{2}\left(4 \%\right.$ in $\mathrm{Ar}$ ) gas and next $\mathrm{CO}_{2}$ gas into $10 \%$ ethanol and $90 \%$ water & 200 & \\
\hline $\mathrm{H}_{2}\left(4 \%\right.$ in $\mathrm{Ar}$ ) gas and next $\mathrm{CO}_{2}$ gas into $20 \%$ ethanol and $80 \%$ water & 220 & \\
\hline $\mathrm{H}_{2}\left(4 \%\right.$ in $\mathrm{Ar}$ ) gas and next $\mathrm{CO}_{2}$ gas into $50 \%$ ethanol and $50 \%$ water & 200 & \\
\hline $\mathrm{CO}_{2}$ gas into water & 115 & $\mathrm{CO}_{2} 0.88$ \\
\hline $\mathrm{CO}_{2}$ gas into $10 \%$ ethanol and $90 \%$ water & 250 & \\
\hline $\mathrm{CO}_{2}$ gas into $20 \%$ ethanol and $80 \%$ water & 280 & \\
\hline $\mathrm{CO}_{2}$ gas into $50 \%$ ethanol and $50 \%$ water & 260 & \\
\hline $\mathrm{CO}_{2}$ gas into $30 \%$ ethene glycol and $70 \%$ water & 430 & \\
\hline $\mathrm{CO}_{2}$ gas into $50 \%$ ethene glycol and $50 \%$ water & 730 & \\
\hline $\mathrm{CO}_{2}$ gas into water and then $\mathrm{H}_{2}(4 \%$ in $\mathrm{Ar}$ ) gas into water & 130 & \\
\hline $\mathrm{CO}_{2}$ gas and next $\mathrm{H}_{2}(4 \%$ in $\mathrm{Ar}$ ) gas into $10 \%$ ethanol and $90 \%$ water & 200 & \\
\hline $\mathrm{CO}_{2}$ gas and next $\mathrm{H}_{2}(4 \%$ in $\mathrm{Ar}$ ) gas into $20 \%$ ethanol and $80 \%$ water & 460 & \\
\hline $\mathrm{CO}_{2}$ gas and next $\mathrm{H}_{2}(4 \%$ in $\mathrm{Ar}$ ) gas into $50 \%$ ethanol and $50 \%$ water & 400 & \\
\hline $\mathrm{O}_{2}$ gas in water & 150 & $\mathrm{O}_{2} 0.031$ \\
\hline $\mathrm{N}_{2}$ gas in water & 180 & $\mathrm{~N}_{2} 0.016$ \\
\hline
\end{tabular}

Table 1. Mean diameters of the nanobubble produced by blowing gases into water, ethanol, and ethylene glycol solution through porous ceramics for every $30 \mathrm{~min}$.

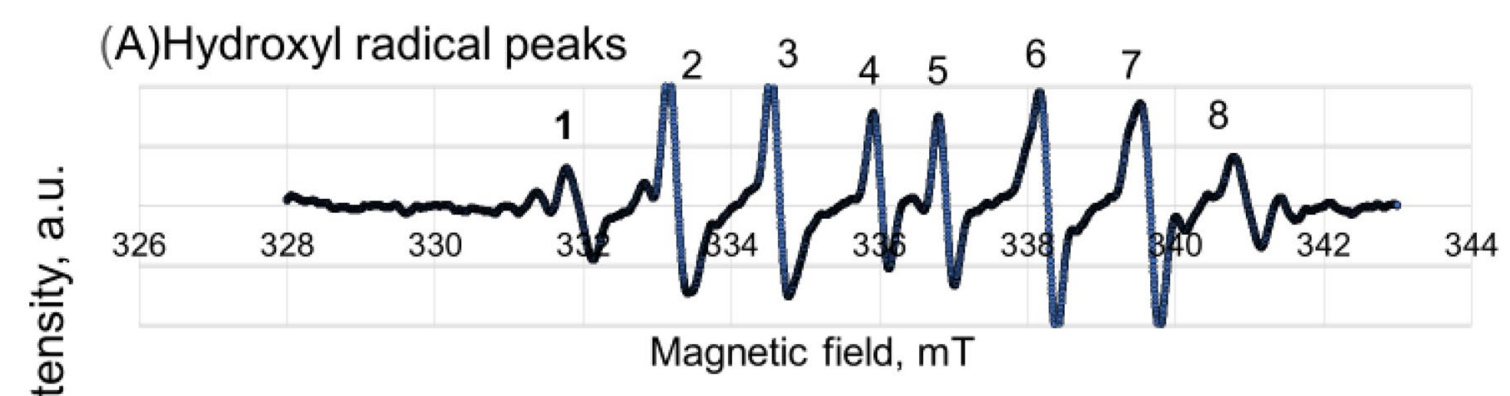

(B)Superoxide anion peaks

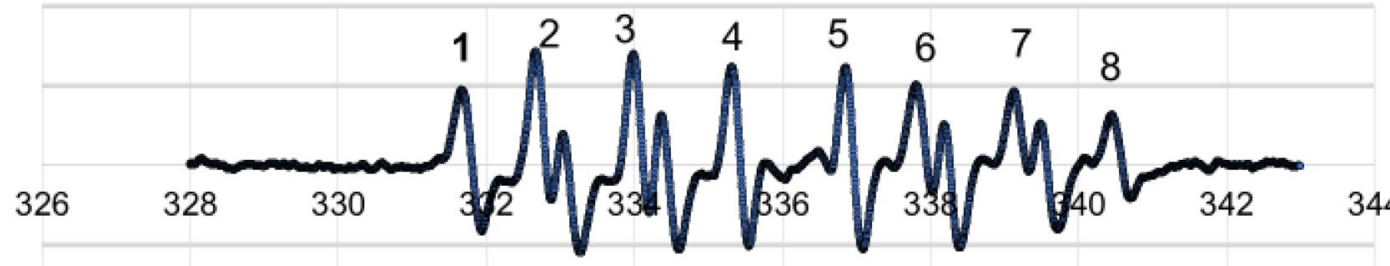

\section{Magnetic field, mT}

Figure 1. Comparison between hydroxyl radical (A) and superoxide anion (B) peaks.

Hydroxyl radical degradation in alcohol aqueous solution. The $\mathrm{CO}_{2}$ and $\mathrm{H}_{2}$ (4\% in $\mathrm{Ar}$ ) are blown into 50\%, 20\%, and $10 \%$ of ethanol in water with $0.1 \% \mathrm{H}_{2} \mathrm{O}_{2}$. The peaks of hydroxyl radical with ESR are shown in Fig. 4 . The $\mathrm{H}_{2}$ (4\% in $\mathrm{Ar}$ ) gas bubbling reduced hydroxyl radical small. While the $\mathrm{CO}_{2}$ gas bubbling reduced hydroxyl radical almost completely in the used concentration of ethanol aqueous solution. The $\mathrm{CO}_{2}$ nanobubble in ethanol aqueous solution can eliminate the hydroxyl radical. The $\mathrm{CO}_{2}$ and $\mathrm{H}_{2}$ ( $4 \%$ in Ar) have been blown into $50 \%$ and $30 \%$ of ethylene glycol in water with $0.1 \% \mathrm{H}_{2} \mathrm{O}_{2}$ as a dihydric alcohol aqueous solution and the peaks are shown 


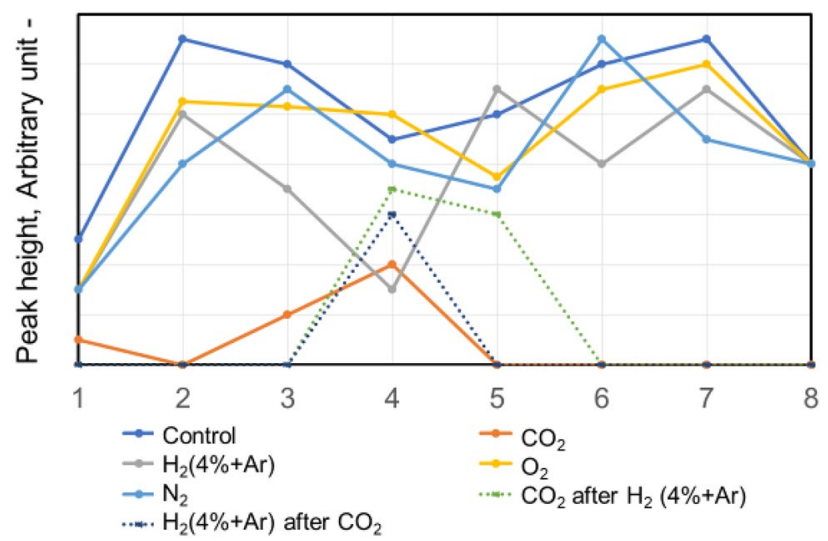

Peak number from low magnetic field of hydroxyl radical by $\mathrm{G}-\mathrm{CYPMPO}$ in $(\mathrm{A})$

Figure 2. Comparison between different kinds of gas nanobubble peak height of peak number from low magnetic field shown in (A) of Fig. 1 of hydroxyl radical by G-CYPMP.

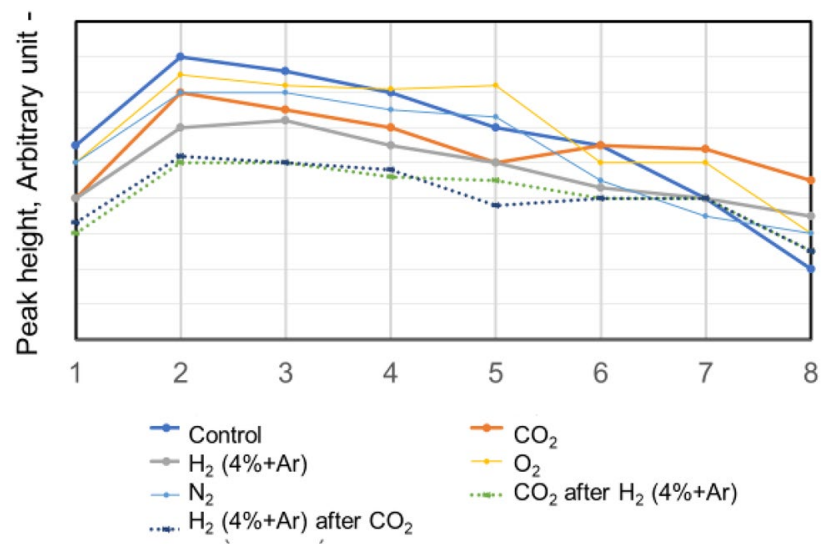

Peak number from low magnetic field of superoxide anion by G-CYPMPO in (B)

Figure 3. Comparison between different kinds of gas nanobubble peak height of peak number of superoxide anions from low magnetic field shown in (B) of Fig. 1 of superoxide anion radical by G-CYPMPO.

in Fig. 5. The $\mathrm{H}_{2}$ (4\% in Ar) gas bubbling can reduce the hydroxyl radical a little bit small, whereas the $\mathrm{CO}_{2}$ gas bubbling eliminates hydroxyl radical almost completely like the result of ethanol aqueous solution. Next, the hydroxyl radical degradation is investigated with the blowing order of $\mathrm{CO}_{2}$ and $\mathrm{H}_{2}$ (4\% in $\mathrm{Ar}$ ) gas. Peaks of hydroxyl radical with ESR by blowing $\mathrm{CO}_{2}$ after $\mathrm{H}_{2}$ (4\% in $\mathrm{Ar}$ ) gas and $\mathrm{H}_{2}$ (4\% in Ar) after $\mathrm{CO}_{2}$ gas nanobubble into 50, 20, and $10 \%$ ethanol with $0.1 \% \mathrm{H}_{2} \mathrm{O}_{2}$ aqueous solution are shown in Fig. 6. Only $\mathrm{H}_{2}(4 \%$ in $\mathrm{Ar}$ ) blowing cannot decrease the hydroxyl radical peak as shown in Fig. 4, however, the $\mathrm{CO}_{2}$ blowing after $\mathrm{H}_{2}(4 \%$ in $\mathrm{Ar}$ ) can disappear the hydroxyl radical peaks as shown in Fig. 6. On the other hand, only $\mathrm{CO}_{2}$ blowing can decrease the hydroxyl radical peaks as shown in Fig. 4, however, the $\mathrm{H}_{2}$ (4\% in Ar) blowing increased the hydroxyl radical peaks again as shown in Fig. 6. For the 50 and 30\% ethylene glycol aqueous solution the same phenomena have appeared. The peaks of hydroxyl radical with ESR by blowing $\mathrm{CO}_{2}$ after $\mathrm{H}_{2}$ (4\% in $\mathrm{Ar}$ ) gas nanobubble and $\mathrm{H}_{2}$ (4\% in Ar) after $\mathrm{CO}_{2}$ gas nanobubble into 50 and $30 \%$ ethylene glycol with $0.1 \% \mathrm{H}_{2} \mathrm{O}_{2}$ aqueous solution is shown in Fig. 7. The $\mathrm{H}_{2}$ (4\% in $\mathrm{Ar}$ ) blowing after $\mathrm{CO}_{2}$ increased the hydroxyl radical peaks again.

Photos of the plate are compared with the control and the solution containing nanobubbles treatment after $48 \mathrm{~h}$ incubation is shown in Fig. 8. The $50 \%$ ethylene glycol with $0.1 \% \mathrm{H}_{2} \mathrm{O}_{2}$ aqueous solution $\mathrm{H}_{2}(4 \%$ in $\mathrm{Ar})$ nanobubble injection after $\mathrm{CO}_{2}$ gas nanobubble blowing showed no living bacteria after $48 \mathrm{~h}$ incubation. The hydroxyl radical in the solution as shown in Fig. 7 had an effect to prevent bacteria from propagating.

Superoxide anion radical degradation in alcohol aqueous solution. The hypoxanthine (HX)/xanthine oxidase (XOD) solution is added and mixed well with $50 \%, 20 \%$, and $10 \%$ of ethanol in water containing $\mathrm{CO}_{2}$ and $\mathrm{H}_{2}$ (4\% in Ar) nanobubbles. Then the peaks of superoxide anion radical with ESR using spin trapping reagent of G-CYPMPO are shown in Fig. 9. The $\mathrm{H}_{2}$ (4\% in Ar) gas and $\mathrm{CO}_{2}$ nanobubble included $10 \%$ and $20 \%$ ethanol 


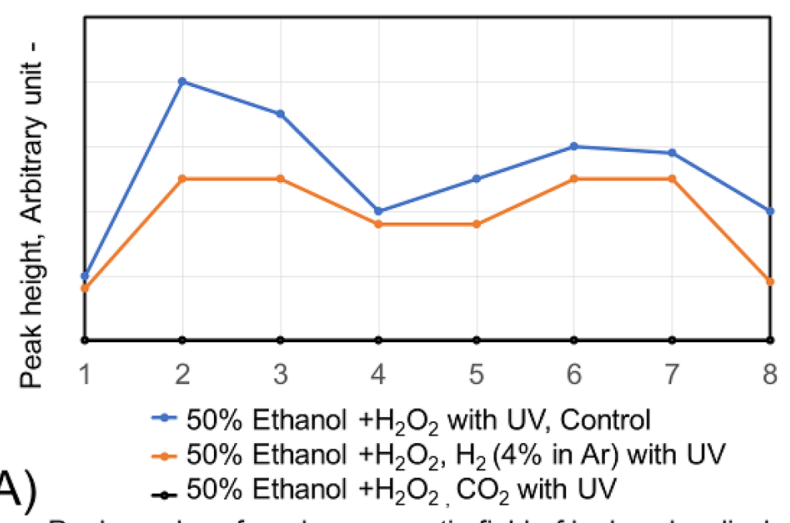

Peak number from low magnetic field of hydroxyl radical by G-CYPMPO in (A)

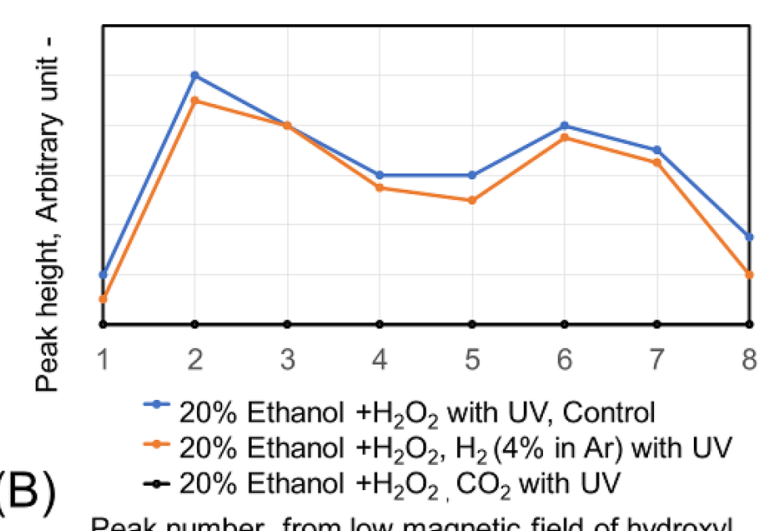

Peak number from low magnetic field of hydroxyl radical by G-CYPMPO in (A)

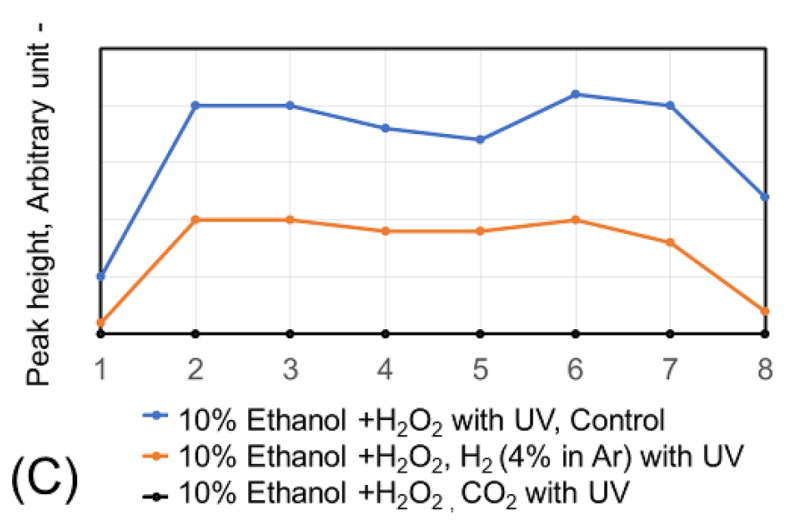

Peak number from low magnetic field of hydroxyl radical by $\mathrm{G}-\mathrm{CY}$ PMPO in (A)

Figure 4. Peaks of hydroxyl radical with ESR by blowing $\mathrm{CO}_{2}$ and $\mathrm{H}_{2}$ (4\% in Ar) gas nanobubble into 10, 20, and $50 \%$ ethanol with $0.1 \% \mathrm{H}_{2} \mathrm{O}_{2}$ aqueous solution.

aqueous solution reduced superoxide anion radical slightly. However, radical degradation cannot be seen in the $50 \%$ ethanol aqueous solution. The peaks of superoxide anion radical with ESR in 30 and 50\% ethylene glycol aqueous solution containing $\mathrm{CO}_{2}$ and $\mathrm{H}_{2}$ (4\% in Ar) nanobubble are shown in Fig. 10. For the 50 and $30 \%$ ethylene glycol aqueous solution, radical degradation is very small. The $30 \%$ ethylene glycol aqueous solution containing $\mathrm{H}_{2}$ ( $4 \%$ in $\mathrm{Ar}$ ) nanobubble shows much smaller peaks, however, the $\mathrm{CO}_{2}$ peaks do not decrease. Next, the superoxide anion radical degradation is investigated with the blowing order of $\mathrm{CO}_{2}$ and $\mathrm{H}_{2}$ (4\% in $\mathrm{Ar}$ ) gas nanobubble in ethanol aqueous solution. The peaks of superoxide anion radical with ESR by blowing $\mathrm{CO}_{2}$ after $\mathrm{H}_{2}$ (4\% in $\mathrm{Ar}$ ) gas nanobubble and $\mathrm{H}_{2}$ (4\% in $\mathrm{Ar}$ ) after $\mathrm{CO}_{2}$ gas nanobubble into 50, 20, and $10 \%$ ethanol aqueous solution are shown in Fig. 11. Comparing the control, in the combination liquid of $\mathrm{CO}_{2}$ after $\mathrm{H}_{2}(4 \%$ in $\mathrm{Ar}$ ) for 20 and 10\% ethanol aqueous solution, the superoxide anion decreased comparing the peaks by only $\mathrm{CO}_{2}$ and $\mathrm{H}_{2}$ 


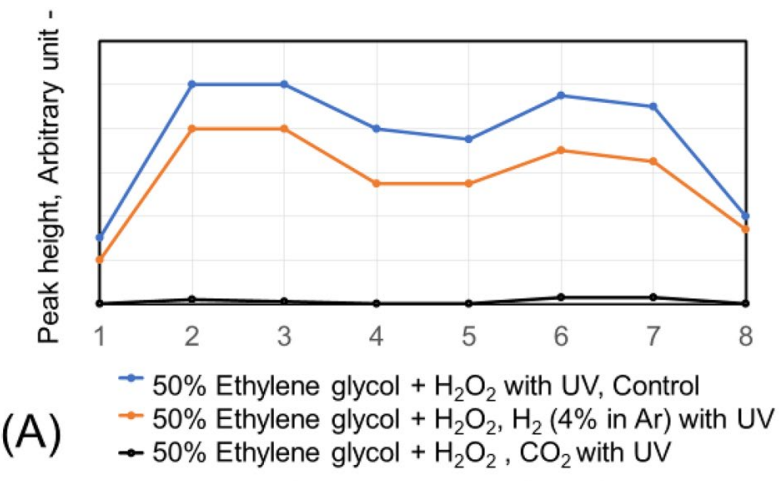

Peak number from low magnetic field of hydroxyl radical by G-CYPMPO in $(A)$

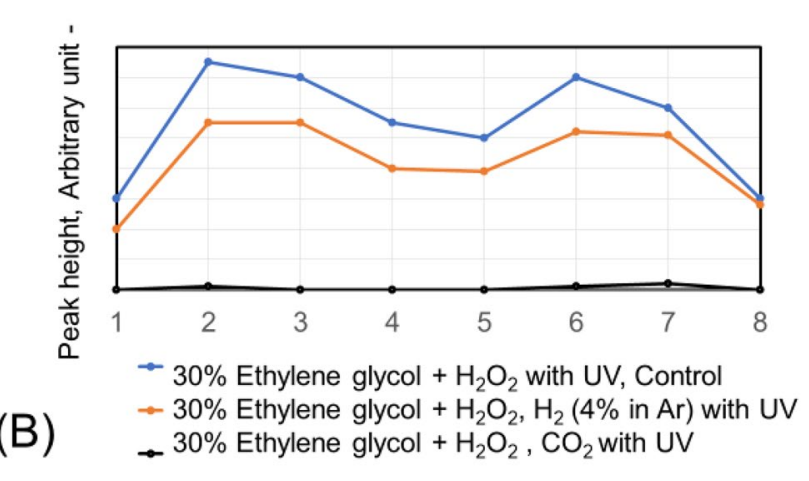

Peak number trom low magnetıc tield ot hydroxyl radical by G-CYPMPO in (A)

Figure 5. Peaks of hydroxyl radical with ESR by blowing $\mathrm{CO}_{2}$ and $\mathrm{H}_{2}$ (4\% in Ar) gas nanobubble into 30 and $50 \%$ ethylene glycol with $0.1 \% \mathrm{H}_{2} \mathrm{O}_{2}$ aqueous solution.

(4\% in Ar) in Fig. 9. The ethylene glycol aqueous solution is investigated with the blowing order. The peaks of superoxide anion radical with ESR by blowing $\mathrm{CO}_{2}$ after $\mathrm{H}_{2}$ ( $4 \%$ in $\mathrm{Ar}$ ) gas nanobubble and $\mathrm{H}_{2}$ ( $4 \%$ in $\mathrm{Ar}$ ) after $\mathrm{CO}_{2}$ gas nanobubble into 50 and $30 \%$ ethylene glycol aqueous solution are shown in Fig. 12. The blowing of $\mathrm{CO}_{2}$ gas after $\mathrm{H}_{2}$ (4\% in Ar) gas decreased larger than the $\mathrm{H}_{2}$ (4\% in Ar) gas after $\mathrm{CO}_{2}$ gas for 50 and $30 \%$ ethylene glycol aqueous solution. This is a similar phenomenon to the 20 and $10 \%$ ethanol aqueous solution.

\section{Discussion}

There are some reports for the diminishment of free radicals by hydrogen nanobubble as shown in the introduction session. The hydrogen nanobubble scavenged various ROS $^{18}$ and reduced especially hydroxyl radical ${ }^{15,17}$. Oxygen nanobubble caused tissue damage ${ }^{16}$. In this experiment, the used solvents are pure water, ethanol aqueous solution as monohydric alcohol, and ethylene glycol aqueous solution as a dihydric alcohol mixture. The hydroxyl radical $(\cdot \mathrm{HO})$ is produced by adding $\mathrm{H}_{2} \mathrm{O}_{2}$ in an aqueous solution and irradiation of UV as shown in the Eq. (1). The superoxide anion $\left(\cdot \mathrm{O}_{2}^{-}\right)$was produced with an addition of hypoxanthine (HX) and xanthine oxidase (XO) in an aqueous solution. In the measurement of hydroxyl radical by ESR with UV, a large amount of $\mathrm{CO}_{2}$ and $\mathrm{H}_{2}$ nanobubbles are supplied into $\mathrm{H}_{2} \mathrm{O}_{2}$ added aqueous solution before measurement. While the superoxide anion was measured by ESR after the superoxide anion was mixed with $\mathrm{O}_{2}$ and $\mathrm{H}_{2}$ nanobubble containing aqueous solution. Some parts of $\mathrm{CO}_{2}$ and $\mathrm{H}_{2}$ nanobubbles are collapsed and the appeared gas seems to react to the radicals. There is a report that $\mathrm{N}_{2}, \mathrm{O}_{2}$ and $\mathrm{CO}_{2}$ nanobubbles produced by piston-type generator have gradually changed the size for $48 \mathrm{~h}^{21}$. After nanobubbles were produced, in a few days nanobubble size of $\mathrm{N}_{2}$, $\mathrm{O}_{2}$, and $\mathrm{H}_{2}+\mathrm{Ar}$ changes and becomes almost constant in a week and stable. However, the $\mathrm{CO}_{2}$ gas bubble size constantly changes larger and disappeared in several days. The nanobubble gas can supply the gas reacts to the radicals for several days. Several chemical formula ${ }^{22}$ of hydroxyl radical and superoxide anion radical reactions with hydrogen and oxygen are as follows,

$$
\begin{gathered}
\mathrm{H}_{2} \mathrm{O}_{2} \text { UV irradiation } \rightarrow 2 \cdot \mathrm{HO} \\
\cdot \mathrm{HO}+\mathrm{CO}_{2} \rightarrow \cdot \mathrm{CO}_{3} \mathrm{H} \\
\cdot \mathrm{CO}_{3} \mathrm{H}+\mathrm{H}_{2} \mathrm{O} \rightarrow \mathrm{H}_{2} \mathrm{CO}_{3}+\mathrm{OH}^{-}
\end{gathered}
$$




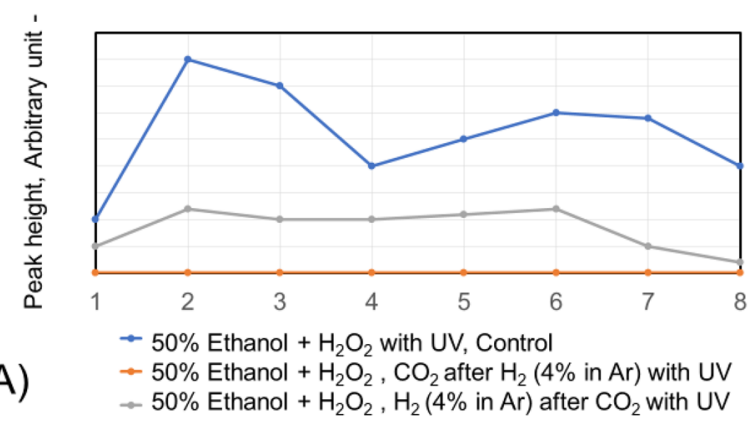

Peak number from low magnetic field of hydroxyl radical by G-CYPMPO in (A) of

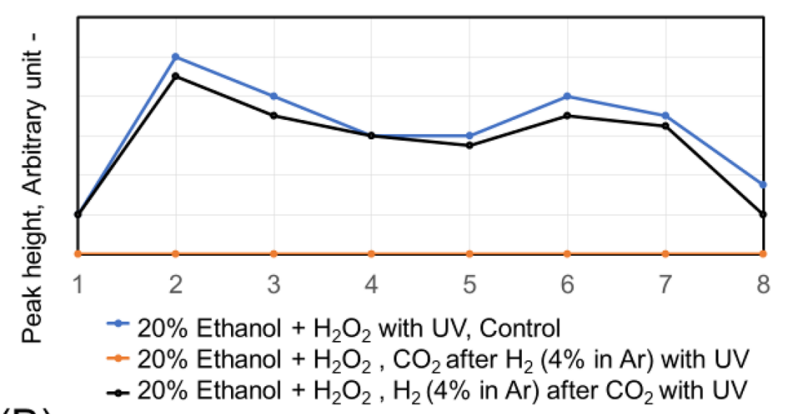

(B) Peak number from low magnetic field of hydroxyl radical by G-CYPMPO in (A) of

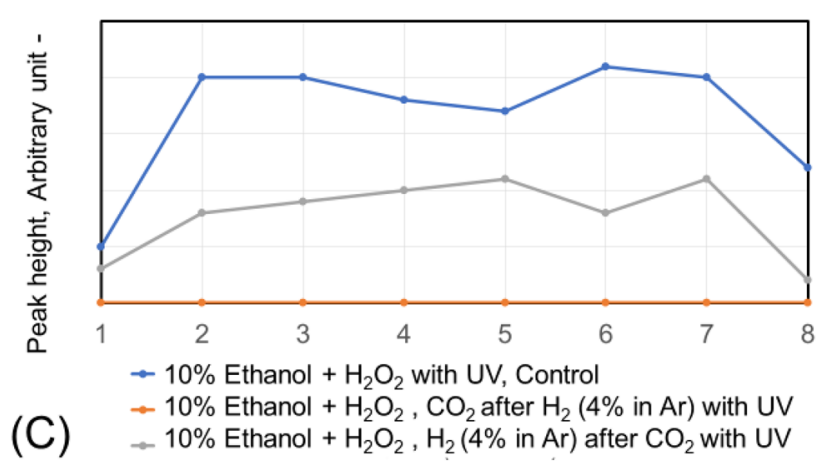

Peak number from low magnetic field of hydroxyl radical by G-CYPMPO in (A)

Figure 6. Peaks of hydroxyl radical with ESR by blowing $\mathrm{CO}_{2}$ after $\mathrm{H}_{2}$ (4\% in Ar) gas nanobubble and $\mathrm{H}_{2}(4 \%$ in $\mathrm{Ar}$ ) after $\mathrm{CO}_{2}$ gas nanobubble into 50, 20, and $10 \%$ ethanol with $0.1 \% \mathrm{H}_{2} \mathrm{O}_{2}$ aqueous solution.

$$
\begin{gathered}
\mathrm{H}_{2} \mathrm{CO}_{3} \Leftrightarrow \mathrm{HCO}_{3}^{-}+\mathrm{H}^{+} \\
\mathrm{H}^{+}+\mathrm{OH}^{-} \rightarrow \mathrm{H}_{2} \mathrm{O} \\
\cdot \mathrm{O}_{2}^{-}+\mathrm{H}_{2} \rightarrow 2 \cdot \mathrm{HO} \\
\cdot \mathrm{HO}+\mathrm{H}_{2} \mathrm{O}_{2} \rightarrow \cdot \mathrm{HO}_{2}+\mathrm{H}_{2} \mathrm{O} \\
\cdot \mathrm{HO}_{2} \Leftrightarrow \mathrm{H}^{+}+\cdot \mathrm{O}_{2}^{-} \\
2 \mathrm{H}_{2} \mathrm{O}_{2} \rightarrow 2 \mathrm{H}_{2} \mathrm{O}+\mathrm{O}_{2} \\
\mathrm{H}_{2} \mathrm{O}_{2}+\cdot \mathrm{O}_{2}^{-} \rightarrow \cdot \mathrm{HO}+\mathrm{OH}^{-}+\mathrm{O}_{2}
\end{gathered}
$$



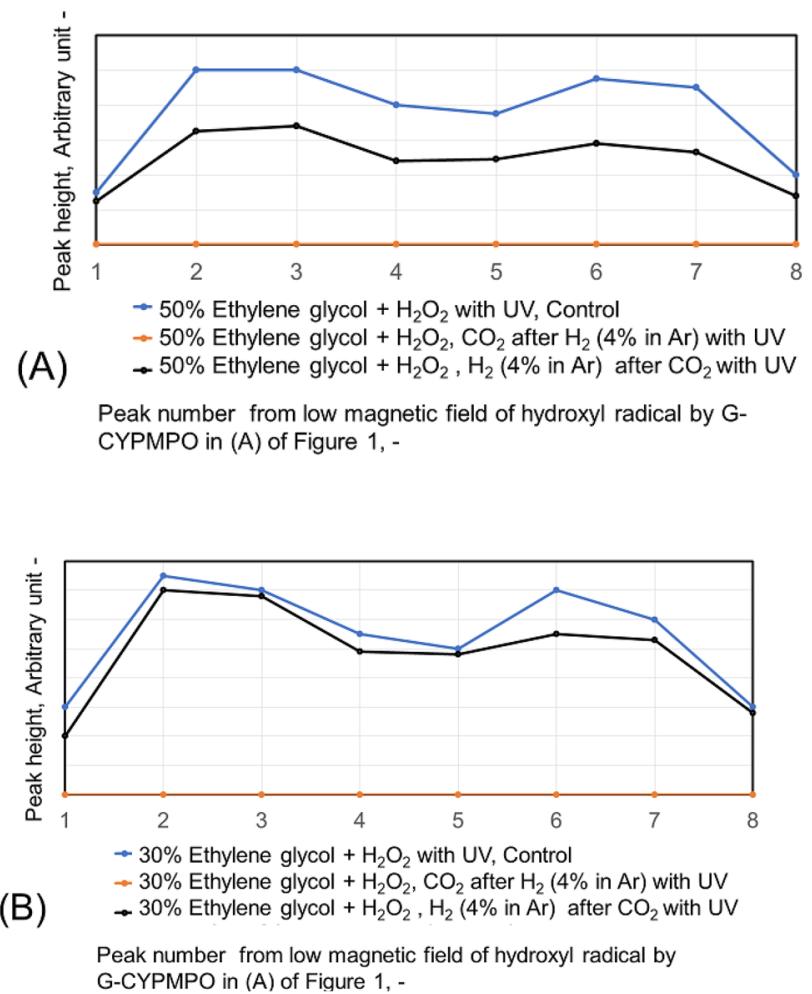

Figure 7. Peaks of hydroxyl radical with ESR by blowing $\mathrm{CO}_{2}$ after $\mathrm{H}_{2}$ (4\% in Ar) gas nanobubble and $\mathrm{H}_{2}(4 \%$ in $\mathrm{Ar}$ ) after $\mathrm{CO}_{2}$ gas nanobubble into 50 and $30 \%$ ethylene glycol with $0.1 \% \mathrm{H}_{2} \mathrm{O}_{2}$ aqueous solution.

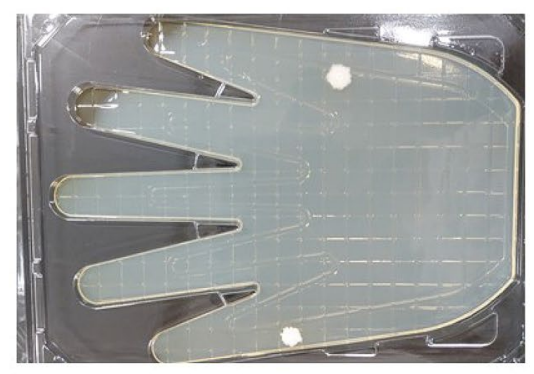

48 hours incubated after treatment in $50 \%$ Ethylene glycol aqueous solution with $0.1 \% \mathrm{H}_{2} \mathrm{O}_{2}$ of $\mathrm{H}_{2}$ (4\% in $\mathrm{Ar}$ ) nanobubble after $\mathrm{CO}_{2}$ nanobubble blowing.

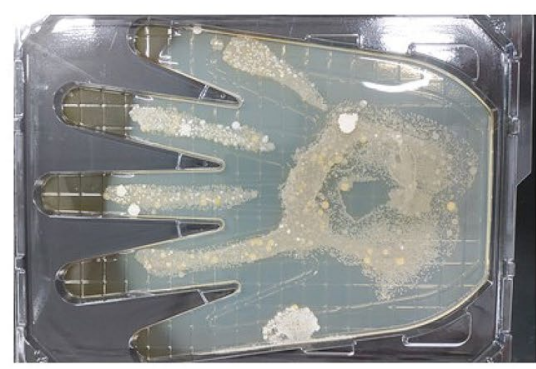

48 hours incubated as control

Figure 8. Photos of the plate are compared with the control and the solution containing nanobubbles treatment after $48 \mathrm{~h}$ of incubation.

$$
\begin{gathered}
2 \cdot \mathrm{O}_{2}^{-}+2 \mathrm{H}^{+} \rightarrow \mathrm{H}_{2} \mathrm{O}_{2}+\mathrm{O}_{2} \\
\mathrm{CH}_{3} \mathrm{CH}_{2}(\mathrm{OH})+\cdot \mathrm{O}_{2}^{-}+\mathrm{H}_{2} \rightarrow \cdot \mathrm{HO}+\mathrm{H}_{2} \mathrm{O}+\mathrm{CH}_{3} \mathrm{CH}_{2}\left(\mathrm{O}^{-}\right) \\
\mathrm{HOCH}_{2} \mathrm{CH}_{2} \mathrm{OH}+\cdot \mathrm{O}_{2}^{-}+\mathrm{H}_{2} \rightarrow \cdot \mathrm{HO}+\mathrm{H}_{2} \mathrm{O}+\left(\mathrm{O}^{-}\right) \mathrm{CH}_{2} \mathrm{CH}_{2} \mathrm{OH}
\end{gathered}
$$

The decrease of the ESR spectrum of $\cdot \mathrm{HO}$ in aqueous solution with $\mathrm{CO}_{2}$ nanobubble is shown in the reaction $(2) \rightarrow(3) \rightarrow(4) \rightarrow(5)$, therefore, $\cdot \mathrm{H}$ O can be reduced. However, by blowing $\mathrm{H}_{2}$ ( $4 \%$ in $\left.\mathrm{Ar}\right), \mathrm{O}_{2}$, and $\mathrm{N}_{2}$ nanobubble it is difficult to react directly to $\cdot \mathrm{HO}$ in an aqueous solution. As shown in the ESR peaks of Fig. 2, only $\mathrm{CO}_{2}$ nanobubble can reduce the $\cdot \mathrm{HO}$ in water. Also, the $\mathrm{CO}_{2}$ nanobubble can reduce $\cdot \mathrm{OH}$ in the other alcohol aqueous solution as shown in Figs. 4 and 5. In Figs. 6 and 7, the $\mathrm{CO}_{2}$ blowing after $\mathrm{H}_{2}$ (4\% in Ar) gas nanobubble showed a clear decrease in the peak of $\cdot \mathrm{HO}$ similar to only $\mathrm{CO}_{2}$ blowing. On the other hand, the opposite mixing of $\mathrm{H}_{2}$ 


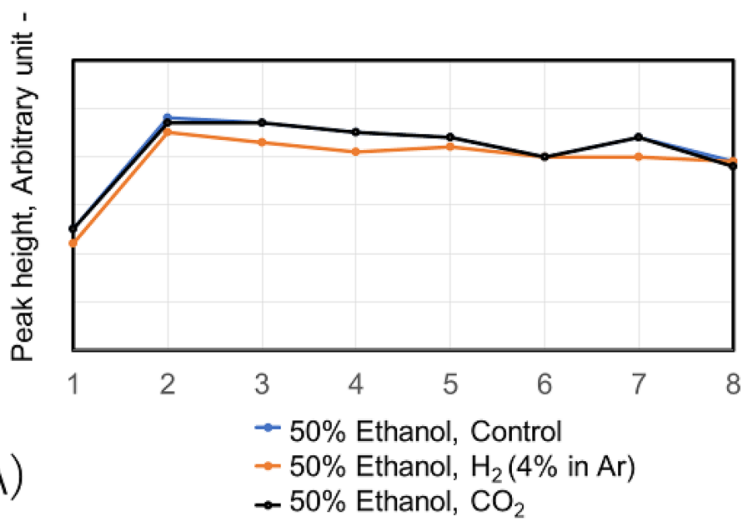

Peak number from low magnetic field of superoxide anion by G-CYPMPO in (B)

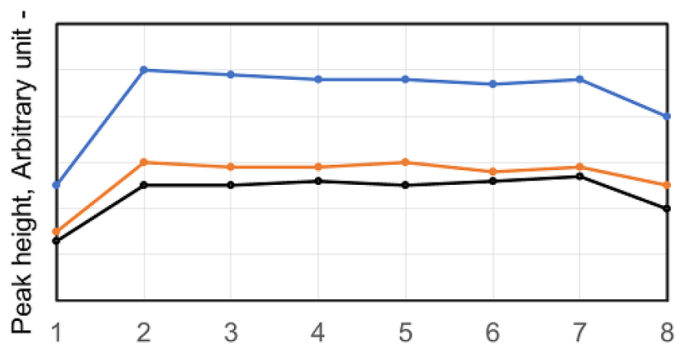

(B)

$\rightarrow 20 \%$ Ethanol, Control

$-20 \%$ Ethanol, $\mathrm{H}_{2}(4 \%$ in $\mathrm{Ar}$ )

$\rightarrow 20 \%$ Ethanol, $\mathrm{CO}_{2}$

Peak number from low magnetic field of superoxide anion by G-CYPMPO in (B)

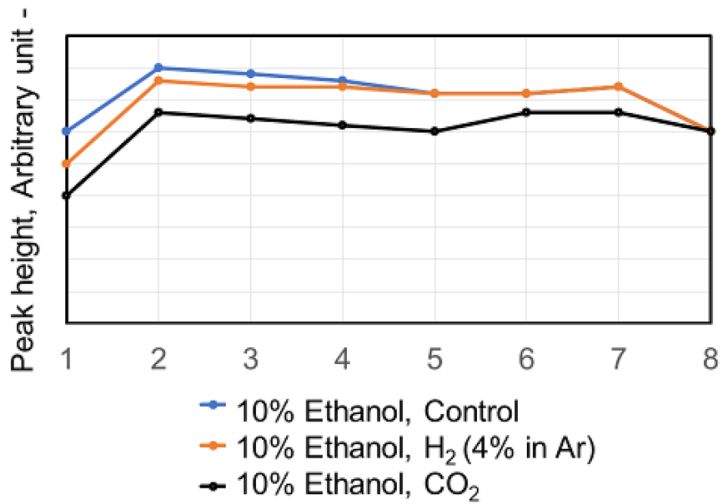

Peak number from low magnetic field of superoxide anion by G-CYPMPO in (B)

Figure 9. Peaks of superoxide anion radical with ESR in 10, 20, and 50\% ethanol aqueous solution containing $\mathrm{CO}_{2}$ and $\mathrm{H}_{2}(4 \%$ in $\mathrm{Ar})$ nanobubble.

(4\% in $\mathrm{Ar}$ ) gas nanobubble after $\mathrm{CO}_{2}$ blowing did not decrease the peak of $\cdot \mathrm{HO}$ and $\mathrm{H}_{2}$ (4\% in $\mathrm{Ar}$ ) nanobubble increased the peak of $\cdot \mathrm{HO}$. The produced $\cdot \mathrm{O}_{2}^{-}$shown in the Eqs. (7) and (8) reacts with $\mathrm{H}_{2}$ and $\cdot \mathrm{HO}$ is produced again by the reaction shown in Eq. (6). The reaction of $\cdot \mathrm{O}_{2}^{-}$in aqueous solution with $\mathrm{H}_{2}(4 \%$ in $\mathrm{Ar}$ ) nanobubble is shown in the reaction (6) and the ESR peaks of $\cdot \mathrm{O}_{2}^{-}$with $\mathrm{H}_{2}$ nanobubble in water decreases slightly comparing with other $\mathrm{O}_{2}, \mathrm{~N}_{2}$, and $\mathrm{CO}_{2}$ nanobubble as shown in Fig. 3. Next, the $\cdot \mathrm{O}_{2}^{-}$has mixed with water containing $\mathrm{CO}_{2}$ and $\mathrm{H}_{2}$ (4\% in Ar) nanobubble. The produced $\cdot \mathrm{HO}$ in (6) can be reduced by the $\mathrm{CO}_{2}$ nanobubble in the reaction of $(2) \rightarrow(3) \rightarrow(4) \rightarrow(5)$. When $\mathrm{H}_{2}$ (4\% in $\mathrm{Ar}$ ) nanobubble is blowing into ethanol and ethylene glycol with water, $\cdot \mathrm{HO}$ is produced by the reaction (12) and (13). When the $\cdot \mathrm{O}_{2}{ }^{-}$has mixed with both $\mathrm{CO}_{2}$ and $\mathrm{H}_{2}(4 \%$ in Ar) nanobubble mixed solution, the peaks of. 


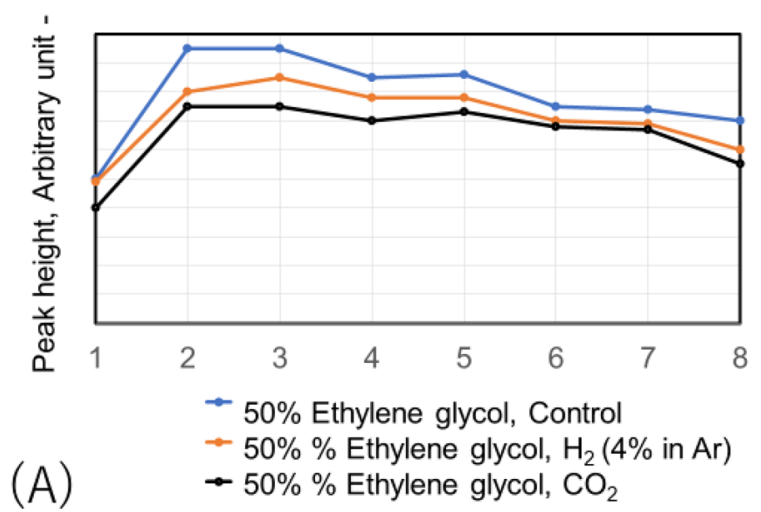

Peak number from low magnetic field of superoxide anion by G-CYPMPO in (B)

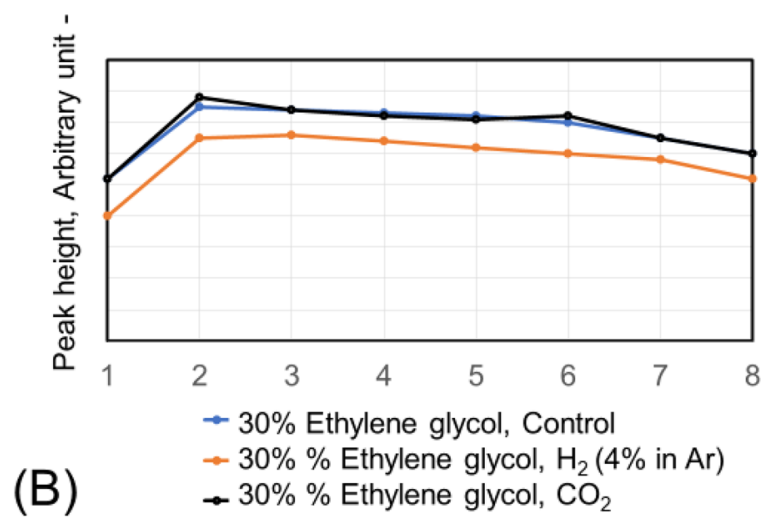

Peak number from low magnetic field of superoxide anion by G-CYPMPO in (B)

Figure 10. Peaks of superoxide anion radical with ESR in 30 and 50\% ethylene glycol aqueous solution containing $\mathrm{CO}_{2}$ and $\mathrm{H}_{2}$ (4\% in $\mathrm{Ar}$ ) nanobubble.

$\cdot \mathrm{O}_{2}{ }^{-}$has decreased clearly in the ethanol aqueous solution as shown in Fig. 10. While the peaks of $\cdot \mathrm{O}_{2}{ }^{-}$have decreased slightly in the ethylene glycol aqueous solution as shown in Fig. 11. The larger $\mathrm{H}_{2}$ nanobubble amount by $\mathrm{H}_{2}\left(4 \%\right.$ in Ar) blowing after $\mathrm{CO}_{2}$ gas nanobubble might contribute to the reaction $(6) \rightarrow(7) \rightarrow(8)$ and increase $\cdot \mathrm{O}_{2}{ }^{-}$. The degradation of hydroxyl radical and superoxide anion as a free radical of active oxygen has been investigated. The $\mathrm{CO}_{2}$ nanobubble inclusion after $\mathrm{H}_{2}$ nanobubble injection into water and ethanol aqueous solution including hydroxyl radical and superoxide radical can reduce the free radical in aqueous solution and this phenomenon might contribute as a healthy beverage. On the other hand, the hydrogen nanobubble inclusion after $\mathrm{CO}_{2}$ nanobubble injection can increase the free radical in ethylene glycol aqueous solution shown in Fig. 7 . When the ethanol and ethylene glycol containing $\mathrm{H}_{2} \mathrm{O}_{2}$ produces $\cdot \mathrm{OH}$ with $\mathrm{UV}$. The $\mathrm{CO}_{2}$ nanobubble decreases $\cdot \mathrm{OH}$ by the reaction $(2) \rightarrow(3) \rightarrow(4)$. Next remaining $\mathrm{H}_{2} \mathrm{O}_{2}$ produces $\cdot \mathrm{O}_{2}^{-}$by the reaction (7) and (8). When ethanol and ethlenglycol exist with $\cdot \mathrm{O}_{2}^{-}, \mathrm{H}_{2}$ gas from $\mathrm{H}_{2}$ nanobubble generating by blowing $\mathrm{H}_{2}$ produces $\cdot \mathrm{OH}$ as shown in (12) and (13). These phenomena will be useful to kill the bacteria, etc. and the photos in Fig. 8 have been indicated.

\section{Methods}

Nanobubble production. Nanobubbles are generated by blowing the different gas $\left(4 \% \mathrm{H}_{2}\right.$ in $\operatorname{argon}(\mathrm{Ar})$, $\mathrm{CO}_{2}, \mathrm{O}_{2}$, and $\mathrm{N}_{2}$ ) from the gas cylinder into distilled water, ethanol, and ethylene glycol aqueous solution through a porous ceramic sparger of $500 \mathrm{~nm}$ mean pore diameter for $30 \mathrm{~min}^{23}$. Next, the aqueous solutions containing $\mathrm{H}_{2}$ (4\% in $\mathrm{Ar}$ ) gas are blown $\mathrm{CO}_{2}$ gas again and the solution containing $\mathrm{CO}_{2}$ nanobubbles is blown $\mathrm{H}_{2}(4 \%$ in $\mathrm{Ar}$ ) gas again to investigate the effect of nanobubble gas mixture. The nanobubble size distributions are measured by the dynamic light scattering (DLS) method (Otsuka Electronics Co., Ltd.). The prepared nanobubble solution is supplied in the radical experiment within $24 \mathrm{~h}$. In this experiment, a $4 \%$ hydrogen in argon is used to produce the nanobubble for the security as the $4 \mathrm{vol} \%$ hydrogen is the lower explosive limit. The carbon dioxide from the gas cylinder is more than $99.5 \mathrm{vol} \%$. The existing nanobubble percentage in water is about $0.1 \mathrm{vol} \%$ after blowing $30 \mathrm{~min}$. The nanobubble is blown in the water, $50 \%, 20 \%$, and $10 \%$ ethanol as monohydric alcohol in water and $50 \%, 30 \%$ ethylene glycol as dihydric alcohol in water. 


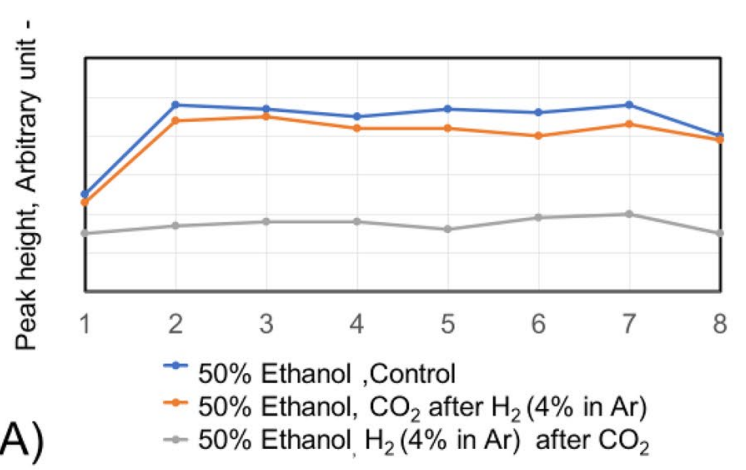

Peak number from low magnetic field of superoxide anion by G-CYPMPO in (B)

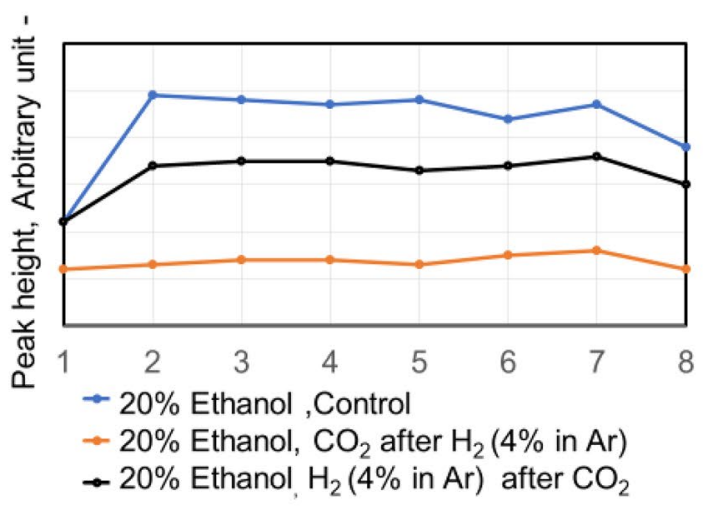

Peak number from low magnetic field of superoxide anion by G-CYPMPO in (B)

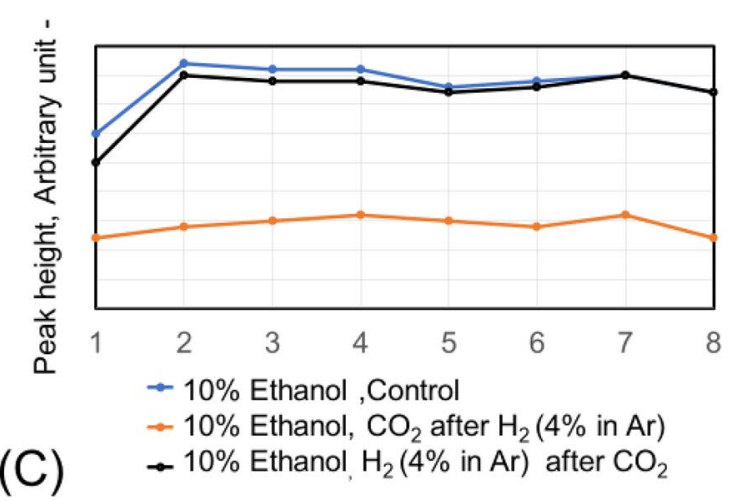

Peak number from low magnetic field of superoxide anion by G-CYPMPO in (B)

Figure 11. Peaks of superoxide anion radical with ESR by blowing $\mathrm{CO}_{2}$ after $\mathrm{H}_{2}$ (4\% in Ar) gas nanobubble and $\mathrm{H}_{2}$ (4\% in $\mathrm{Ar}$ ) after $\mathrm{CO}_{2}$ gas nanobubble into 50,20 , and $10 \%$ ethanol aqueous solution.

Radical production. The hydroxyl radical is produced with $0.1 \mathrm{wt} \% \mathrm{H}_{2} \mathrm{O}_{2}$ addition in aqueous solution and 10 -s ultraviolet irradiation. The superoxide anion was produced with a hypoxanthine (HX) and xanthine oxidase (XO) system. A mixture of $3.6 \mu \mathrm{L}$ of 10.97 units/ml XO, $20 \mu \mathrm{l}$ of $20 \mu \mathrm{M} \mathrm{HX}, 156.4 \mu \mathrm{L}$ of the nanobubble sample solution, and $20 \mu \mathrm{l}$ spin trapping reagent solution are mixed.

As spin-trapping reagent, sc-5-(5,5-dimethyl-2-oxo-1,3,2-dioxapho-sphinan-2-yl)-5 methyl-1-pyrroline $\mathrm{N}$-oxide (G-CYPMPO) ${ }^{24}$ has been used. CYPMPO can spin-trap superoxide and hydroxyl radicals and the halflife for the superoxide adduct of CYPMPO produced in UV-illuminated hydrogen peroxide solution and HX/ $\mathrm{XO}$ solution are about $15 \mathrm{~min}$ and $50 \mathrm{~min}$, respectively ${ }^{25}$. The kinetic evaluation of spin trapping rate constants of CYPMPO was reported ${ }^{26}$. The $0.1 \mathrm{wt} \% \mathrm{H}_{2} \mathrm{O}_{2}$ was added to the aqueous solution before blowing gas bubbles. While the superoxide anion was added after blowing the gas bubbles. 


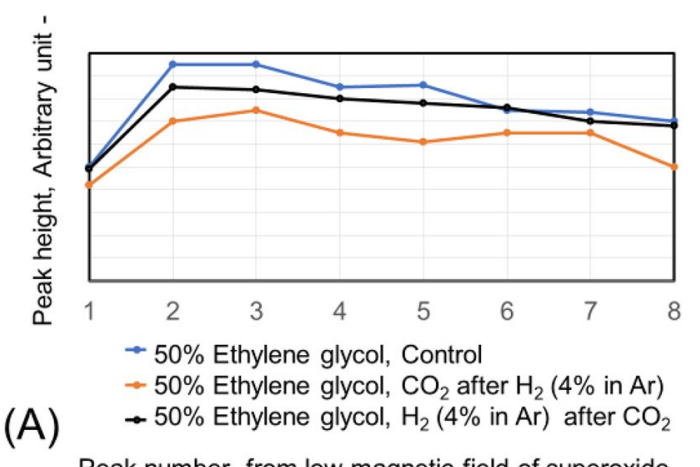

Peak number from low magnetic field of superoxide anion by G-CYPMPO in (B)

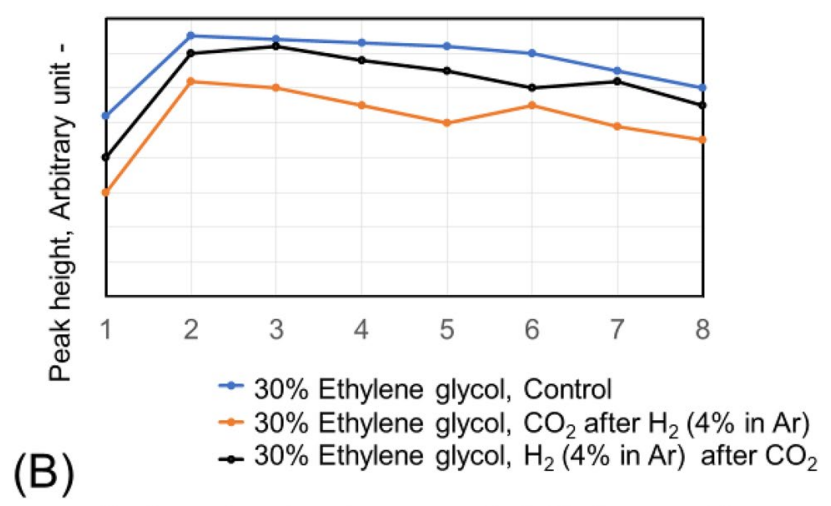

Peak number from low magnetic field of superoxide anion by G-CYPMPO in (B)

Figure 12. Peaks of superoxide anion radical with ESR by blowing $\mathrm{CO}_{2}$ after $\mathrm{H}_{2}$ ( $4 \%$ in $\mathrm{Ar}$ ) gas nanobubble and $\mathrm{H}_{2}$ (4\% in Ar) after $\mathrm{CO}_{2}$ gas nanobubble into 50 and $30 \%$ ethylene glycol aqueous solution.

Measurement of radical existence. JEOL JES-TE25X ESR spectrometer is used to obtain ESR spectra of free radicals of hydroxyl radical and superoxide anion. To investigate the decomposition of hydroxyl radicals by nanobubbles, the various gas has been blown into $0.1 \mathrm{wt} \% \mathrm{H}_{2} \mathrm{O}_{2}$ added aqueous solution, and the spectra of hydroxyl radicals by ESR is measured. While to decompose the superoxide anion, the superoxide anion is added into the various nanobubbles included aqueous solution and the spectra of superoxide anion have been measured by ESR.

Disinfection tests. Hand Petancheck II Tryptone Soya Agar Medium [Eiken Chemical Co., Ltd. ${ }^{27}$ is used to measure the total number of living bacteria on hand. The hand is put into an aqueous solution containing viable bacteria and touch the plate. The plate is incubated for $48 \mathrm{~h}$ as control. The other plate is soaked with ethylene glycol aqueous solution containing nanobubble and after removing the solution the plate is incubated for $48 \mathrm{~h}$. After $48 \mathrm{~h}$ the photos of the plate are compared with the control and the solution containing nanobubbles treatment.

Received: 2 September 2020; Accepted: 5 January 2021

Published online: 04 February 2021

\section{References}

1. Takahashi, M., Chiba, K. \& Li, P. Free-radical generation from collapsing microbubbles in the absence of a dynamic stimulus. J. Phys. Chem. B 111, 1343-1347. https://doi.org/10.1021/jp0669254 (2007).

2. Li, P., Takahashi, M. \& Chiba, K. Technical note degradation of phenol by the collapse of microbubbles. Chemosphere 75 , 13711375. https://doi.org/10.1016/j.chemosphere.2009.03.031 (2009).

3. Li, P., Takahashi, M. \& Chiba, K. Enhanced free-radical generation by shrinking microbubbles using a copper catalyst. Chemosphere 77, 1157-1160. https://doi.org/10.1016/j.chemosphere.2009.07.062 (2009).

4. Takahashi, M., Horibe, H., Matsuura, K. \& Tatera, K. Effect of microbubbles on ozonized water for photoresist removal. J. Photopolym. Sci. Technol. 28, 293-298 (2015).

5. Michailidi, E. D., Bomis, G., Varoutoglou, A. C., Kyzas, G. Z. \& Mitrikas, G. Bulk nanobubbles: Production and investigation of theirformation/stability mechanism. J. Colloid Interface Sci. 564, 371-380. https://doi.org/10.1016/j.jcis.2019.12.093 (2020).

6. Wanga, L. et al. Oxygen nanobubbles enhanced photodegradation of oxytetracycline undervisible light: Synergistic effect and mechanism. Chem. Eng. J. 388, 124227. https://doi.org/10.1016/j.cej.2020.124227 (2020). 
7. Tada, K. et al. ESR measurement of hydroxyl radicals in micro-nanobubble water. Chem. Lett. 43, 1907-1908. https://doi. org/10.1246/cl.140691 (2014).

8. Ahmed, A. K. B. et al. Influences of air, oxygen, nitrogen, and carbon dioxidenanobubbles on seed germination and plant growth. J. Agric. Food Chem. 66(20), 5117-5124. https://doi.org/10.1021/acs.jafc.8b00333 (2018).

9. Kim, M., Song, S. H., Kim, W. D. \& Han, J. G. An experimental study on bubble collapsing effect ofnanobubble using ultrasonic wave. J. Nanosci. Nanotechnol. 20, 636-642. https://doi.org/10.1166/jnn.2020.17280 (2020).

10. Ashutosh, A., Wun, J. N. \& Yu, L. Review principle and applications of microbubble and nanobubble technology for water treatment. Chemosphere 84, 1175-1180. https://doi.org/10.1016/j.chemosphere.2011.05.054 (2011).

11. Atkinson, A. J., Apul, O. G. \& Schneider, O. Nanobubble technologies offer opportunities to improve water treatment. Accounts Chem. Res. 52, 1196-1205. https://doi.org/10.1021/acs.accounts.8b00606 (2019).

12. Tekile, A., Kim, I. \& Lee, J. Y. Applications of ozone micro- and nanobubble technologies in water and wastewater treatment: review. J. Korean Soc. Water Wastewater 31, 481-490. https://doi.org/10.11001/jksww.2017.31.6.481 (2017).

13. Tao, L., Shubiao, W., Robert, J. G., Mortimer, A. \& Gang, P. Nanobubble technology in environmental engineering: revolutionization potential and challenges. Environ. Sci. Technol. 53, 7175-7176. https://doi.org/10.1021/acs.est.9b02821 (2019).

14. Orela, V. B., Zabolotnyb, M. A. \& Ore, V. E. Heterogeneity of hypoxia in solid tumors and mechanochemical reactions with oxygen nanobubbles. Med. Hypotheses 102, 82-86. https://doi.org/10.1016/j.mehy.2017.03.006 (2017).

15. Asada, R. et al. Antitumor effects of nano-bubble hydrogen-dissolved water are enhanced by coexistent platinum colloid and the combined hyperthermia with apoptosis-like cell death. Oncol. Rep. 24, 1463-1470. https://doi.org/10.3892/or_00001006 (2010).

16. Matsuki, N. et al. Oxygen supersaturated fluid using fine micro/nanobubbles. Int. J. Nanomed. 9, 4495-4505. https://doi. org/10.2147/IJN.S68840 (2014).

17. Kato, S., Matsuoka, D. \& Miwa, N. Antioxidant activities of nano-bubble hydrogen-dissolved water assessed by ESR and 2,2'-bipyridyl methods. Mater. Sci. Eng. C 53, 7-10. https://doi.org/10.1016/j.msec.2015.03.064 (2015).

18. Liu, S., Oshita, S., Thuyet, D. Q., Saito, M. \& Yoshimoto, T. Antioxidant activity of hydrogen nanobubbles in water with different reactive oxygen species both in vivo and in vitro. Langmuir 34, 11878-11885. https://doi.org/10.1021/acs.langmuir.8b02440 (2018).

19. Kurokawa, H. et al. Antioxidant effect of hydrogen nanobubble contributes to suppression of tumor cell growth. Biomed. J. Sci. Tech. Res. 19, 14592-14594. https://doi.org/10.26717/BJSTR.2019.19.003361 (2019).

20. National Astronomical Observatory of Japan, Chronological Scientific Tables, 517 (2015)

21. Wang, Q. et al. Generation and stability of size-adjustable bulk nanobubbles based on periodic pressure change. Sci. Rep. 9, 1118. https://doi.org/10.1038/s41598-018-38066-5 (2019).

22. Sawaki, Y. Advances in the reactions of active oxygen species. J. Oleo Sci. 1, 471-478 (2001).

23. Fujita, T. et al. Nano bubble and emulsion size distribution measurement by interactive force apparatus. Int. J. Soc. Mater. Eng. Resour. 23, 158-161. https://doi.org/10.5188/ijsmer.23.158 (2018).

24. Oka, T. et al. Spin-trapping reactions of a novel gauchetype radical trapper G-CYPMPO. Anal. Chem. 83, 9600-9604. https://doi. org/10.1021/ac2023926 (2011).

25. Kamibayashi, M., Oowada S., Kamada, H., Okada, T., Inanami, O., Ohta, S., Ozawa, T., Makino, K. \& Kotake, Y. Synthesis and characterization of a practically better DEPMPO-type spin trap, 5-(2,2-dimethyl-1.3-propoxy cyclophosphoryl)-5-methyl-1-pyrroline N-oxide (CYPMPO). Free Rad. Res. 40, 1162-1172. https://doi.org/10.1080/10715760600883254 (2006)

26. Sueishi, Y. et al. Kinetic evaluation of spin trapping rate constants of new CYPMPO-type spin traps for superoxide and other free radicals. Z. Phys. Chem. 299, 317-326. https://doi.org/10.1515/zpch-2014-0610 (2014).

27. EIKEN CHEMICAL CO., LTD., https://www.eiken.co.jp/uploads/product/industry/pamph/HAND.pdf, (2014)

\section{Acknowledgements}

The useful information received by Mr. Chikara Suzuki (Bell Packe Co., Ltd.) and Mr. Kazuaki Tasaka (Innovridge Co., Ltd.) are greatefully acknowleged. One part of this work was supported by the National Natural Science Foundation of China [Grant number 21976039].

\section{Author contributions}

T.F. and H.K. designed the study. Z.H. and Y.Z. measured the nanobubble size distribution, H.K. and H.M. measured the ESR. J.P. and G.D. prepared the nanobubble solution. C.H. and Y.W. discussed the research. All authors participated in the discussion to interpret the results, and T.F. and G.D. wrote the paper.

\section{Competing interests}

The authors declare no competing interests.

\section{Additional information}

Correspondence and requests for materials should be addressed to T.F. or Y.W.

Reprints and permissions information is available at www.nature.com/reprints.

Publisher's note Springer Nature remains neutral with regard to jurisdictional claims in published maps and institutional affiliations.

Open Access This article is licensed under a Creative Commons Attribution 4.0 International License, which permits use, sharing, adaptation, distribution and reproduction in any medium or
format, as long as you give appropriate credit to the original author(s) and the source, provide a link to the Creative Commons licence, and indicate if changes were made. The images or other third party material in this article are included in the article's Creative Commons licence, unless indicated otherwise in a credit line to the material. If material is not included in the article's Creative Commons licence and your intended use is not permitted by statutory regulation or exceeds the permitted use, you will need to obtain permission directly from the copyright holder. To view a copy of this licence, visit http://creativecommons.org/licenses/by/4.0/.

(C) The Author(s) 2021 